\title{
Influence of Steel Fiber Content of RPC Flexural Fatigue Life
}

\author{
Mao Lin, Yanfeng Tian, Xiaoqing Yu and Gongli Hu \\ Gulou District of Xuzhou City, West Club Street, No. 86,Jiangsu,China
}

\begin{abstract}
In order to study the influence of steel fiber ratios on RPC flexural fatigue life, this paper obtained flexural fatigue loading times of RPC with different steel fiber ratio through flexural fatigue test. The results show that the fatigue property of RPC with steel fiber is improved significantly compared with plain RPC. The fatigue damage evolution is divided into three stages; The fatigue equations are established which correlation coefficient are all above 0.95 through Weibull distribution test and linear regression of RPC fatigue life, which indicates the flexural fatigue life of RPC obey the Weibull distribution.
\end{abstract} life

Keywords-RPC; steel fiber ratios; flexural fatigue test; fatigue

\section{INTRODUCTION}

Reactive Powder Concrete (RPC) is a kind of super-highstrength, low-permeability and high-durability cement-based ultra-high performance concrete developed by French Bouygues Company in the 1990s. Compared with the ordinary concrete, it has $3 \sim 12$ times the strength and about 250 times the ductility [1], in the construction, marine, military protection engineering has broad application prospects.

Buildings or structures are often subject to the role of cyclic loads, such as roads, bridges, offshore drilling platforms. Under the action of cyclic loading, the internal defects of the structure gradually expand to degrade the structure and cause the material to fatigue damage under the load less than the static load. Therefore, the study of anti-fatigue properties of materials is very necessary. At present, the domestic research on RPC is mainly concentrated in the mix design, static performance, durability and other aspects [2-4], its fatigue resistance is relatively small. Fang Zhi [5] and other one-way compression by constant-amplitude fatigue test of the steel fiber content of reactive powder concrete anti-fatigue properties of the test results show that the addition of steel fibers can significantly improve the anti-fatigue properties of RPC; The fatigue strength, fatigue deformation and fatigue modulus of singleratio RPC under uniaxial compressive load were studied. The fatigue life equation was established. In this paper, four kinds of steel fiber content (volume fraction of $0 \%, 1 \%, 2 \%$ and $3 \%$ ) RPC anti-fatigue test to study the impact of steel fiber content on the flexural fatigue resistance of RPC.

\section{TEST OVERVIEW}

\section{A. Raw materials and mix}

Cement with PO 42.5 ordinary portland cement, measured $28 \mathrm{~d}$ compressive strength of $49.7 \mathrm{Mpa}$; silica fume of the average particle size of $0.1 \mu \mathrm{m}, \mathrm{SiO} 2$ content of not less than $90 \%$; fly ash for the first-class fly ash; Diameter range of 0 $1.25 \mathrm{~mm}$ grading standard sand; high water-reducing agent selection of new non-naphthalene water-reducing agent, solid content of $30 \%$, water reduction rate of $29 \%$; steel fiber diameter $0.18-0.2 \mathrm{~mm}, 12 \mathrm{~mm}$ surface of the flat copper-plated steel fiber, tensile strength $2850 \mathrm{Mpa}$.

In order to study the effect of steel fiber content on the fatigue resistance of RPC, the content of steel fiber is $0 \%, 1 \%$, $2 \%$ and $3 \%$, respectively, S0, S1, S2 and S3. Table I shows the test mix.

TABLE I. TEST MIX

\begin{tabular}{|c|c|c|c|c|}
\hline cement & $\begin{array}{c}\text { Silica } \\
\text { fume }\end{array}$ & Fly ash & sand & Superplasticizer \\
\hline 1.0 & 0.2 & 0.15 & 1.62 & $3 \%$ \\
\hline
\end{tabular}

B. Manufacture and Maintenance of Specimen

The components were accurately weighed according to the test mix. First of all, the cement, silica fume and fly ash and other cementitious materials into the mixer, dry mixing $2 \mathrm{~min}$, followed by the standard sand and steel fibers, dry mixing $2 \mathrm{~min}$, the mixture to achieve macro-uniform distribution of mixed with high efficiency water reduction Half of the water, stir $3 \mathrm{~min}$, and finally into the other half of the water, rapid mixing $5 \mathrm{~min}$, the mixture into the $40 \mathrm{~mm} \times 40 \mathrm{~mm} \times 160 \mathrm{~mm}$ mold, vibrating molding, standing in the standard curing room $24 \mathrm{~h}$ after the mold release into the standard curing Box curing to 28d. Each group produced nine specimens, of which three specimens for the determination of flexural strength, six specimens for bending fatigue test.

\section{Experiment Method}

Three-point bending test was carried out to apply cyclic loading with a span of $120 \mathrm{~mm}$. The load mode is sinusoidal, the frequency is $5 \mathrm{~Hz}$, the maximum stress level of the three groups is 0.85 , and the minimum stress level is 0.15 (the stress level $\mathrm{S}$ is the ratio of the applied stress $\sigma$ to the flexural ultimate bearing capacity fc).

\section{TEST RESUlTS AND ANALYSIS}

\section{A. Flexural test results}

The flexural strength and flexural strength of the three specimens in each group were measured and the average values were recorded as shown in Table II. 
TABLE II. FLEXURAL STRENGTH OF THE SPECIMEN

\begin{tabular}{|c|c|c|c|c|}
\hline $\begin{array}{c}\text { Experimental } \\
\text { grouping }\end{array}$ & S0 & S1 & S2 & S3 \\
\hline $\begin{array}{c}\text { Bending } \\
\text { resistance limit } \\
\text { Bearing } \\
\text { capacity/kN }\end{array}$ & 6.18 & 8.22 & 9.79 & 11.23 \\
\hline $\begin{array}{c}\text { Flexural } \\
\text { strength/MPa }\end{array}$ & 11.59 & 15.42 & 18.36 & 21.05 \\
\hline
\end{tabular}

B. The Results of Flexural Fatigue Test and Weibull Distribution Test

In the process of cyclic loading, RPC exhibits obvious brittle failure characteristics, with the occurrence and development of macro-cracks, RPC soon lose its load-bearing capacity. RPCs with steel fibers exhibit obvious plastic failure characteristics, With the increase of the number of load cycles, the crack growth is retarded by the "bridging" effect of the steel fibers after the occurrence of the macro-cracks at the mid-span, and the greater the content of the steel fibers, the more obvious is the effect of the crack propagation. Steel fiber is pulled out, cracks gradually extended through until the specimen damage. The fatigue failure process of RPC is similar to that of ordinary concrete. The first stage is the formation of internal defect nucleation and the initial formation of damage. The inner defects of RPC are gradually gathered under the action of load, and the second stage is the stage of fracture stability expansion. After the formation of macroscopic cracks, the cracks continue to merge and expand gradually; the third stage is loss Stable failure stage, with the steel fiber is constantly pulled out, the sharp increase in cross-strain, fracture through the fatigue failure occurs.

Table II shows the load parameters of the flexural fatigue test in each group. Table II shows the loading times and the Weibull distribution test of the cyclic loading. Table III shows the linear regression of the test results. The regression equation and the correlation coefficient are shown in Table IV.

TABLE III. LOADING FATIGUE RESISTANCE TEST PARAMETERS

\begin{tabular}{|c|c|c|c|c|}
\hline $\begin{array}{c}\text { Experimental } \\
\text { grouping }\end{array}$ & S0 & S1 & S2 & S3 \\
\hline $\begin{array}{c}\text { Upper limit of } \\
\text { load/kN }\end{array}$ & 5.25 & 6.99 & 8.32 & 9.55 \\
\hline $\begin{array}{c}\text { Lower limit of } \\
\text { load/kN }\end{array}$ & 0.92 & 1.23 & 1.47 & 1.68 \\
\hline
\end{tabular}

The probability density function of the Weibull distribution function is:

$$
\begin{gathered}
f(N)=\frac{b}{N_{\alpha}}\left(\frac{N}{N_{a}}\right)^{b-1} \exp \left[-\left(\frac{N}{N_{\alpha}}\right)^{\mathrm{b}}\right](N \geq 0) \\
P\left(N>N_{P}\right)=\exp \left[-\left(\frac{N}{N_{\alpha}}\right)^{b}\right]
\end{gathered}
$$

Where: $\mathrm{N}$ is the fatigue life, $\mathrm{Na}$ is the characteristic life parameter; $b$ is the Weibull shape parameter.
Equation (2) can be changed to

$$
\frac{1}{P}=\exp \left(\frac{N}{N_{\alpha}}\right)^{b}
$$

take two natural logarithms on both sides at the same time:

$$
\ln \left[\ln \left(\frac{1}{p}\right)\right]=b \ln N-b \ln N_{a}
$$

Make $Y=\ln \left[\ln \left(\frac{1}{p}\right)\right] ; X=\ln N ; \mathrm{a}=b \ln N_{a}$;

Then

$$
\mathrm{Y}=\mathrm{bX}-\mathrm{a}
$$

(4) is a straight line. If the experimental data show that there is a significant linear relationship between $\ln [\ln (1 / \mathrm{p})]$ and, the assumption is that the flexural fatigue life of RPC obeys the Weibull distribution.

For a given stress level, the number of load cycles in the flexural fatigue test is arranged in order from small to large, and the corresponding survival rate for the fatigue life $\mathrm{N}$ is:

$$
p=1-\frac{i}{1+K}
$$

\begin{tabular}{|c|c|c|c|c|c|}
\hline $\begin{array}{l}\text { Specimen } \\
\text { grouping }\end{array}$ & $\begin{array}{c}\text { Specimen } \\
\text { Number }\end{array}$ & $\mathbf{N}$ & $\ln N$ & $\begin{array}{c}\mathbf{p}=1- \\
{[\mathbf{i} /(1+K)]}\end{array}$ & $\begin{array}{c}\ln [\ln (1 / p \\
)]\end{array}$ \\
\hline \multirow{6}{*}{ S0 } & 1 & 59 & 4.0775 & 0.8571 & -1.8698 \\
\hline & 2 & 172 & 5.1475 & 0.7143 & -1.0892 \\
\hline & 3 & 218 & 5.3845 & 0.5714 & -0.5805 \\
\hline & 4 & 632 & 6.4489 & 0.4286 & -0.1657 \\
\hline & 5 & 915 & 6.8189 & 0.2857 & 0.2254 \\
\hline & 6 & 1086 & 6.9903 & 0.1429 & 0.6657 \\
\hline \multirow{6}{*}{ S1 } & 1 & 974 & 6.8814 & 0.8571 & -1.8698 \\
\hline & 2 & 2905 & 7.9742 & 0.7143 & -1.0892 \\
\hline & 3 & 5572 & 8.6255 & 0.5714 & -0.5805 \\
\hline & 4 & 7011 & 8.8552 & 0.4286 & -0.1657 \\
\hline & 5 & 9369 & 9.1452 & 0.2857 & 0.2254 \\
\hline & 6 & 12031 & 9.3952 & 0.1429 & 0.6657 \\
\hline \multirow{6}{*}{ S2 } & 1 & 2204 & 7.6980 & 0.8571 & -1.8698 \\
\hline & 2 & 3973 & 8.2873 & 0.7143 & -1.0892 \\
\hline & 3 & 7015 & 8.8558 & 0.5714 & -0.5805 \\
\hline & 4 & 9452 & 9.1540 & 0.4286 & -0.1657 \\
\hline & 5 & 11926 & 9.3865 & 0.2857 & 0.2254 \\
\hline & 6 & 14142 & 9.5569 & 0.1429 & 0.6657 \\
\hline \multirow{6}{*}{ S3 } & 1 & 2767 & 7.9255 & 0.8571 & -1.8698 \\
\hline & 2 & 5128 & 8.5425 & 0.7143 & -1.0892 \\
\hline & 3 & 9432 & 9.1519 & 0.5714 & -0.5805 \\
\hline & 4 & 13795 & 9.5321 & 0.4286 & -0.1657 \\
\hline & 5 & 15010 & 9.6165 & 0.2857 & 0.2254 \\
\hline & 6 & 17381 & 9.7631 & 0.1429 & 0.6657 \\
\hline
\end{tabular}

Where: $\mathrm{i}$ is the ordinal number in ascending order, $\mathrm{K}$ is the sample size of each group of specimens.

TABLE IV. WEIBULL DISTRIBUTION TEST OF RPC FATIGUE LIFE 
TABLE V. REGRESSION EQUATION AND CORRELATION COEFFICIENT

\begin{tabular}{|c|c|c|}
\hline $\begin{array}{c}\text { Experimen } \\
\text { tal } \\
\text { grouping }\end{array}$ & $\begin{array}{c}\text { Regression } \\
\text { equation }\end{array}$ & Correlation coefficient \\
\hline S0 & $\mathrm{y}=0.7948 \mathrm{x}-5.0876$ & 0.9638 \\
\hline S1 & $\mathrm{y}=0.9759 \mathrm{x}-8.7443$ & 0.9597 \\
\hline S2 & $\mathrm{y}=1.2816 \mathrm{x}-11.777$ & 0.9804 \\
\hline S3 & $\mathrm{y}=1.2483 \mathrm{x}-11.814$ & 0.9544 \\
\hline
\end{tabular}

Linear regression results show that the correlation coefficient $\mathrm{R}$ is above 0.95 , indicating that $\ln [\ln (1 / \mathrm{p})]$ and the linear relationship between the significant, that the RPC fracture fatigue life subject to Weibull distribution.

The fatigue resistance of RPCs with different steel fiber contents was compared with the survival rate of 0.5 and the number of times of cyclic loading of 5000 times as shown in Table V.

TABLE VI. DIFFERENT STEEL FIBER CONTENT OF RPC ANTIFATIGUE PERFORMANCE COMPARISON

\begin{tabular}{|c|c|c|c|c|}
\hline $\begin{array}{c}\text { Experimental } \\
\text { grouping }\end{array}$ & S0 & S1 & S2 & S3 \\
\hline $\begin{array}{c}\text { And the } \\
\text { survival rate is } \\
\mathbf{0 . 5}\end{array}$ & 380 & 5349 & 7356 & 9609 \\
\hline $\begin{array}{c}\text { Survival rate of } \\
\text { the cycle } \\
\text { loading times of } \\
\mathbf{5 0 0 0}\end{array}$ & 0.005 & 0.5226 & 0.6554 & 0.7359 \\
\hline
\end{tabular}

Compared with RPC, the flexural fatigue performance of $1 \%$ RPC was significantly improved, and the flexural fatigue life was improved with the increase of steel fiber content. The addition of steel fibers significantly improved the flexural fatigue properties of RPC.

in conclusion

In this paper, four kinds of steel fiber content of RPC bending test and bending fatigue test, the following conclusions:

(1) RPC showed the brittle failure. The brittleness of RPC was improved and the toughness was improved. With the increase of steel fiber content, the flexural strength of RPC increased.

(2) The process of flexural fatigue damage of RPC is similar to that of ordinary concrete, showing three stages of development: inner nucleation of nucleation defect, initial formation of damage, expansion of fracture stability and destabilization failure.

(3) Through the Weibull test and the linear regression, the correlation coefficients are more than 0.95 . We can conclude that the fatigue life of RPC is subject to the Weibull distribution.

(4) Compared with RPC, the flexural fatigue performance of $1 \%$ RPC was significantly improved, and with the increase of the content of steel fiber, the fatigue life of flexural fracture was improved.

\section{REFERENCES}

[1] Yang Xiao,Zhao Wei,Jia Qingxiu.The Research Status of Engineered Cementitious Composite.Chinese Polymer Bulletin.2013.(12)
[2] WANG Xiaofei WANG Yangping.Mechanical Properties of RPC with Different Steel Fiber Volume Contents.Journal of Building Materials. 2015.18(6)

[3] DAUD Jumbe R DENG Zongcai.Experimental Study on the Flexural Toughness of RPC Reinforced by Hybrid Fibers.Journal of Building Materials.2015.18(2)

[4] Yang Hui-xian Huang Yan-sheng Li Jing.Dynamic Mechanical Properties of Hybrid Fiber-Reinforced Cement-Based Composites.Journal of South China University of Technology (Natural Science Edition).2015 (7)

[5] WANG Jun WANG Zhi-bin LI Lun.Mechanical Behavior of Reinforced Concrete Short Columns with Steel Fiber RPC Column-permanent Template Subjected to Axial Compression.Journal of Architecture and Civil Engineering.2016 33(2) 